\title{
The effects of total quality management practices on employee performance and the effect of training as a moderating variable
}

\author{
Khaled M.S Abukhader ${ }^{a^{*}}$ and Dilber Çağlar Onbaşıoğlu ${ }^{b}$
}

${ }^{a}$ Graduate School of Social Science, Girne American University, University Drive, PO Box5, 99428, Karmi Campus, Karaoglanoglu, Kyrenia, TRNC, Cyprus ${ }^{b}$ Department of Accounting, Girne American University, University Drive, PO Box5, 99428, Karmi Campus, Karaoglanoglu, Kyrenia, TRNC

\section{H R O N I C L E}

\section{Article history:}

Received April 2, 2021

Received in revised format May

15,2021

Accepted June 102021

Available online

June 142021

Keywords:

$T Q M$

Healthcare

Employee Performance

Training

Turkey \begin{abstract}
A B S T R A C T
This study is carried out to investigate the effect of five factors of the Total quality management practices in healthcare on employee's performance in public hospitals in Turkey. The TQM practices are Top management commitment, customer focus, people management, continuous improvement, and process management. The study adopted a quantitative research method through a survey questionnaire at three public hospitals, 200 valid responses were collected and used as a source of data to test the hypotheses of the study. Hierarchical multiple regression was used for analyzing the collected data, the study indicated that TQM factors have a significant effect on employees' performance and the moderating effect of training has increased the correlation between employees' performance and the TQM factors.
\end{abstract}

(C) 2021 Growing Science Ltd. All rights reserved.

\section{Introduction}

The quality is defined as features built into service, products that meet customer's satisfaction and increase the profit of the provider as well, it also means conformance to specification and free from deficiencies (Deming 2019). Quality has undergone several stages of inspection, followed by quality control and assurance to current TQM (Al-Khalifa \& Aspinwall 2000). Quality is customer-centric, in medical care it is difficult to define, therefore every definition is employed to serve certain problems. The number of patients in a hospital does not always indicate a good service, when a hospital receives many patients, it can be due to its excellent service or because the staff is not doing their job properly (Juran \& Godfrey 1998). Whenever employees are satisfied with their job and have loyalty to their organization they can deliver better service to the external customers, this is dependent on the employee perception about leadership style, HRM, and values that motivates them to increase service performance (Lenka et al., 2010). Quality is determined only by customers, not by marketing nor management. Customer's evaluation is based on experience and the perceived value (Benson et al., 1991). Quality is a comprehensive concept that covers all organizational aspects, through the involvement of all staff members in continuous improvement, integrating quality principles into organization culture (ASQ, 2018). Turkish healthcare public sector has been one of the early adopters of total quality management since 2003, unfortunately, there is no sufficient information about the achieved progress in adopting TQM. Therefore, a need for further research in this field, most of the previous studies lack the focus on employees' performance which reflects the success level of the quality management system. As per literature, the adoption of Total quality management as a managerial system has an influential role in motivating and enhancing employees performance. This study was to determine the effects of TQM on employees' performance and to explore new predictors of TQM adoption.

* Corresponding author Tel.: +5338690577

E-mail address: kabukhader@gmail.com (K. M.S. Abukhader)

(c) 2021 Growing Science Ltd. All rights reserved.

doi: $10.5267 /$ j.uscm.2021.6.010 


\subsection{Organization performance}

Performance measurement has an important role in making employees' aware of what is important for an organization's success and the areas that need to improve, to achieve business excellence, the organization must develop a performance measurement system because effective management is dependent on effective measurement and results (Kanji, 2002). Organizational performance can be measured in a variety of ways, and no single business strategy can be guaranteed to produce the same results across all dimensions. (Walker \& Ruekert, 1987). Top management needs valid information on the performance of the quality management system to be able to regulate the performance and must have access to this information on an ongoing basis instead of waiting for a full review of the QMS to decide whether to intervene and issue actions. (Hoyle 2017). In addition to using practices, companies need to modify their methods of measuring performance in their efforts to achieve business excellence (Kanji 2012a). According to Chang (2006), the presence of innovative approaches to quality management provides more authority and responsibility to employees, therefore monitoring performance is a requirement. TQM based on performance must be measured to evaluate managers' performance, determining performance gaps, defining standards needed for comparisons, and acts as an indication for the cost of poor quality (Zairi 1992). Measurement and reporting of quality level should be on time, the data is used to evaluate performance, setting goals and to evaluate corrective actions, collected information using statistical techniques is used as a basis for improvement objectives (Feigenbaum, 1983). It is believed by many researchers that quality improvements are a strategy for performance improvement in hospitals and the quality of care through a planned systematic approach for continuous improvement (Weiner et al., 2006). Costs related to quality are of more importance than just a financial statement. it is extended to all quality activities; cost of poor quality is like the tip of an iceberg and has the biggest share of costs (Glen et al., 2012). Quality is a long-term strategy that must be monitored for performance and to provide feedback to avoid defects and to sustain continuous improvement which is a core element of TQM (Palo \& Padhi 2003). The importance of measuring organization performance is that it reflects the effectiveness of Total quality management (Idris \& Zairi 2006). In healthcare the quality of medical care is measured through the medical audit to monitor organization performance, the management must have access to all critical information related to performance like, surgeries done, bed occupancy rates, patient satisfaction (Duggirala et al., 2008). Internal audits are supported by top management, employees should be driven by the Key performance indicators results and their supervision by the top manager, who should foster a sense of non-bureaucratic procedure within the organization (Flynn et al., 1995).

\section{Literature review}

\subsection{Top Management Commitment and employee's performance}

When top management follows a participative leadership style, the employees are seen as valuable assets through open communication and involvement which creates loyalty and satisfaction amongst the employees. (Schneider and Bowen 1985). Employee skills and morale can be improved by incorporating practices such as consistent recruiting and training activities, as well as giving workers the opportunity to engage in the business (Ljungström \& Klefsjö 2002) . Goetsch and Davis (2016), stated that a leader has a great role in inspiring and motivating employees through conveying their vision to personnel, providing a clear path for organizational goals and mission, data sharing to ensure that staff is always up to date, Empowering staff and training and mentoring to achieve high performance and efficiency (Galloway 1998) Leaders should not overlook the importance of direct contact with their workers in order to clearly convey obligations, listen to concerns and issues in worker productivity, and respond appropriately (Wheelen \& Hunger 2015). Based on the reviewed literature, the importance of top management commitment is highly emphasized in most of the studies as a main element of TQM and a driver for employees' performance.

\subsection{Customer's focus and employee's performance}

Consumer expectation is affected by employee's experience as a service and organization employee, both roles constitute the organizational practices (both service-related and human-resources related) are affecting Customer perceptions, attitudes, and intentions toward evaluating service quality, management must be aware of its internal operations (Samson \& Terziovski 1999). Ljungström and Klefsjö (2002) confirmed that the combination between TQM and work development is a requirement in removing obstacles toward TQM implementation and achieving satisfaction for both internal and external customers (Rees \& Doran 2001). Balancing between meeting internal customer perception and external customer perception is critical for service quality, The perception of service quality by both groups is highly dependent on different dimensions related to services like Type of customer, frequency, relationship timescale, and service complexity (Goetsch \& Davis, 2016). Companies with a high score on the American Customer Satisfaction Index (ACSI) having higher stock returns and better cash flow than those with low scores of customer satisfaction (Samson \& Terziovski 1999). For any organization to become customer-oriented, it must implement a system that meets customer requirements and queries like contacting the organization easily in an effective manner and learning customers' needs and expectations. Listening to customers only is not effective without putting mechanisms that analyze and interpret the outcomes to act, customer satisfaction for both groups (internal and external) must be treated as a top priority and as the driving force for organizational direction and meeting objectives. 


\subsection{People management and employee's performance}

People management is one of the core practices of TQM to any organization adopting a total quality management system. Human resources policies are a key to successful TQM implementation through the right selection for the candidates, there is an evident relationship between the selection process and TQM, selection procedures must be in line with the quality context (Boer et al., 2017). Employee empowerment is the sense of ownership of the process, this ownership drives the employee to continuously improve the resulting product or service, and an empowered employee is more caring about the quality outcome than the owner or manager (Ahmed et al., 1999). Behavioral factors like commitment and empowerment with open culture can yield a competitive advantage to the organization (Batalden \& Davidoff 2007). In summary, the great role of Human Resources management in managing employees through the right selection of candidates within the quality context is having a critical effect on TQM implementation, organizations need to take a balanced approach toward customer satisfaction and to meet the expectation of both internal and external customers. Communication within the organization at different levels to create healthy relationships among employees, training programs of different purposes and continuous education give room for personal development and equip the staff with the right tools to improve their performance. Finally, employee involvement will increase loyalty and as a motivation to meet the organization's objectives.

\subsection{Continuous improvement and employee's performance}

Continuous improvement is a constant process that engages management and employee interaction to improve the organization's performance, it is regarded as strategic planning for improving organization efficiency as well as the quality of products and services. success level in implementing continuous improvement is mainly dependent on involving all staff members at different hierarchical levels (Jørgensen et al., 2007). The aim of implementing continuous improvement is to improve performance, continuous improvement is an organization-wide planned change program that incorporates current resources and achieved by gradual changes (Lanham et al., 2009). The process of change and improvement is dependent on organizational culture, if the culture has the elements to succeed it can motivate employees to change and improve (LopezSanchez et al., 2009). service is a perspective rather than being an actor, the perceived value is co-created by the customer and provider (Kanji 2012b) Healthcare represents one of the vital service sectors to the community, continuous improvement s collaborative efforts of all stakeholders like healthcare staff, patients and their families, and other stakeholders to create a change that will help in the improvement of the medical care quality and efficiency (Jeston \& Nelis, 2008). Continuous quality improvement that targets one component at a time is found to be less effective in achieving a sustainable improvement, it must be through diverse methods and models (Oakland 2014).

\subsection{Process management and employee's performance}

A process is a set of structured activities that yields a service or a product (Kueng, 2000). A process is defined as a combination of inputs and steps to follow to produce outputs every organization is built upon a complex processes network. (Rad, 2005), early literature has identified three components for process improvement in an organization (people, process, and systems). In recent years systems have been expressed in another term (Technology), people are the key to implement new processes, the process must be linked to organizational strategy. (Jeston \& Nelis 2008). All organizations need good process management for better performance, the underperformance caused by poor process and its linkage with people and technology, every single task in an organization must be viewed as a process and once the process established and meeting the requirements a need for measuring and controlling the process to ensure meeting the organization requirements (Vouzas \& Psychogios 2007). Measuring process performance according to Kueng (2000) is a necessity for organizations, while there is no universal set of performance indicators that fit all business processes, the performance indicator (Zhang et al., 2000). Quality in healthcare is a continuous process, this process must be started, continued, evaluated, improved, and monitored continuously (Sun, 2000). Many organizations blame the employees for poor performance .it is rarely the responsibility of the staff who executed the process, the organization must put in place an improvement plan with the following: making the processes efficient and effective and adding value to the organization strategy, reviewing roles and structure in right possible way to support the new processes and after managing the processes and structure, the employees' performance can be evaluated properly. (Ahmed \& Idris, 2020)

\subsection{Employee performance}

Engaging the employees in the quality process is a fundamental concept in TQM implementation through sharing of information within the organization to encourage the employees to become part of the quality improvement process (Micklewright 2010). Participation of employees by receiving employee's suggestion and after evaluating the validity of their suggestions it should be implemented, this could be through different methods, like using quality circles, cross-sectional team formation and voluntary work (Chelsea Goforth 2015). The reason behind the involvement of employees is that whenever an employee faces a problem, he is in the closest position to it and can make the best decision for the quality improvement process, this means higher responsibilities on employees that require a higher level of skills (Ahmed and Idris 2020). Improving employees' skills through training and education showed that there is a positive correlation between empowerment of employees and job satisfaction and involvement, top management must locate necessary resources to train and educate 
staff about QMS, and in return, the staff must support and conform with QMS in their organizations, this will yield infrastructural long-term advantages (Micklewright, 2010). Training is an ongoing process daily until reaching o the maximum performance (Micklewright, 2010) gaining employee loyalty and satisfaction that must be measured and evaluated periodically, also, focusing on sustainable development of staff services, products, processes, and work environment will be a comprehensive view of quality. (Chelsea Goforth, 2015). Employee skills and morale can be improved by incorporating practices such as consistent recruiting and training activities, as well as giving workers the opportunity to engage in the business (Chelsea Goforth, 2015).

\section{Research model, method and data analysis}

\subsection{Research method and hypothesis}

The proposed model shows the relationship between total quality management and employees' performance and the moderating variable, Training in quality management, as shown in Fig. 1. Similarly, the proposed model illustrates the moderating effect that training has on TQM and employee performance.

The study hypothesized a direct positive relationship between TQM adoption and employees' performance and then investigated the training's moderating effect, the following hypotheses were developed:

Hypothesis 1: TQM practices have a positive impact on employee's performance.

Hypothesis 2: Training in quality management is positively moderating the relationship between TQM and employees' performance.

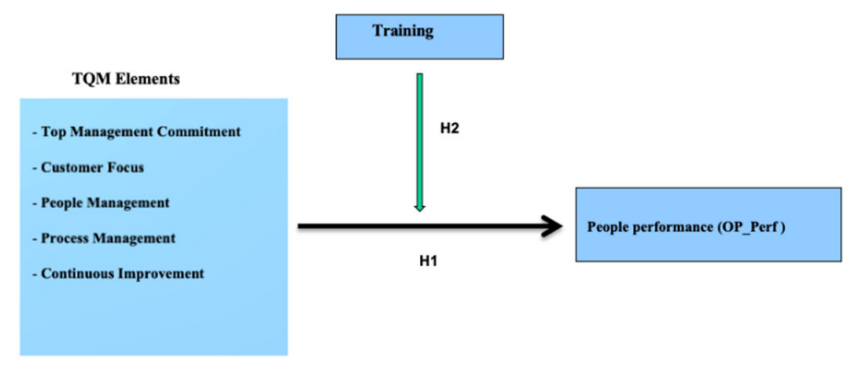

Fig. 1 Research model

\subsection{Reliability of the measurement scale}

Cronbach Alpha was measured to find out the reliability of the measuring tool used for collecting data in this study, the resulting coefficient of reliability ranges from ( 0 to 1 ). Many methodologists suggest a coefficient of 0.65 to 0.8 (or higher in some cases) as a minimum (Chelsea Goforth 2015). In this study, all measured variables Table 1 scored more than 0.7 which is statistically acceptable.

Table 1

Internal consistency coefficient

\begin{tabular}{clccc}
\hline Number & Variable & Cronbach Alpha & Number & Variable \\
\hline 1 & Top Management Commitment & 0.799 & 5 & Cronbach Alpha \\
2 & Customer Focus & 0.798 & 6 & 0.85 \\
3 & People Management & 0.845 & 7 & Training in Quality \\
4 & Continuous Improvement & 0.843 & & People Performance \\
\hline
\end{tabular}

\subsection{Measurement and data analysis}

Independent variables, "TQM implementation" was measured with 40 items representing the five TQM practices, Dependent variables "employees' performance" was measured by 4 items (I am pleased with the career advancement opportunities available to me, Employee morale, Staff involvement in the improvement process, A culture of suggestions for improvement exists, adoption rate to employee suggestions). Quality training was measured by 2 items, the used scale was the five-point Likert scale where 1 is Strongly Disagree and 5 is Strongly Agree.

\section{Empirical results}

Hierarchical Regression analysis was performed to investigate how employees' performances are being affected by the TQM practices. Regression analysis conducted revealed that the model is significant, $F(5,184)=63.287, p<0.01$, (table 2). This is an indication that the regression model contains significant factors. Analysis showed that the average correlation depicting the relationship between top management commitment, customers' focus, employees' management, continuous improvement, 
process management, and the employees' performance is $r=0.795$, (Table 2). This is an indication that there exists an overall positive relationship between these variables. The analysis also revealed an $R$-squared $=63.2 \%$, (Table 2 ), which is an indication that the about 63.2 percent variation in employees' performance can be explained by the explanatory variables. Regression analysis showed in the first stage of the hierarchical model that the model is significant, $F(5,184)=63.287$, (Table 3 ), indicating that the model has factors that have a significant effect on employees' performance. Tables 2 and Table 3 show that all the TQM practices are significantly affecting employees' performance as hypothesized and very consistent with the literature. ( $H_{1}$ : TQM practices have a positive impact on employees' performance).

Table 2

$\underline{\text { Regression Analysis }}$

\begin{tabular}{|c|c|c|c|c|c|c|c|c|c|c|}
\hline \multirow[b]{2}{*}{ Model } & \multirow[b]{2}{*}{$\mathrm{R}$} & \multirow[b]{2}{*}{ R Square } & \multirow[b]{2}{*}{$\begin{array}{l}\text { Adjusted R } \\
\text { Square }\end{array}$} & \multirow[b]{2}{*}{$\begin{array}{l}\text { Std. Error of } \\
\text { the Estimate }\end{array}$} & \multicolumn{5}{|c|}{ Change Statistics } & \multirow[b]{2}{*}{$\begin{array}{l}\text { Durbin- } \\
\text { Watson }\end{array}$} \\
\hline & & & & & $\begin{array}{l}\text { R Square } \\
\text { Change }\end{array}$ & F Change & df1 & $\mathrm{df} 2$ & Sig. F Change & \\
\hline 1 & $.795^{\mathrm{a}}$ & .632 & .622 & .45139 & .632 & 63.287 & 5 & 184 & .000 & \\
\hline 2 & $.825^{\mathrm{b}}$ & .681 & .670 & .42181 & .048 & 27.719 & 1 & 183 & .000 & 1.892 \\
\hline
\end{tabular}

Table 3

Regression Analysis

\begin{tabular}{|c|c|c|c|c|c|c|}
\hline Model & & Sum of Squares & df & Mean Square & $\mathrm{F}$ & Sig. \\
\hline \multirow[t]{3}{*}{1} & Regression & 64.475 & 5 & 12.895 & 63.287 & $.000^{\mathrm{b}}$ \\
\hline & Residual & 37.491 & 184 & .204 & & \\
\hline & Total & 101.967 & 189 & & & \\
\hline \multirow[t]{3}{*}{2} & Regression & 69.407 & 6 & 11.568 & 65.017 & $.000^{c}$ \\
\hline & Residual & 32.559 & 183 & .178 & & \\
\hline & Total & 101.967 & 189 & & & \\
\hline
\end{tabular}

a. Dependent Variable: People performance

b. Predictors: (Constant), Process Management, People Management, Continuous Improvement, Top Management Commitment, Customers Focus c. Predictors: (Constant), Process Management, People Management, Continuous Improvement, Top Management Commitment, Customers Focus, Training in Quality Management

The coefficient Table 4 shows that top management quality is a significant predictor of employees' performance, $b=0.417, t$ $(184)=5.345, p<0.01$. This indicates that a unit change in top management commitment in public health hospitals in Turkey tends to change the employees' performance by 0.417 . The regression model also prompts a positive relationship between top management commitment and employees' performance. The analysis revealed that customers' focus has a significant positive effect on employees' performance, $b=0.201, t(184)=6.342, p=0.014$, (table4). This tells that a unit increase in customers' focus tends to increase the employees' performance by 0.201 .

Table 4

Hierarchical Regression Analysis

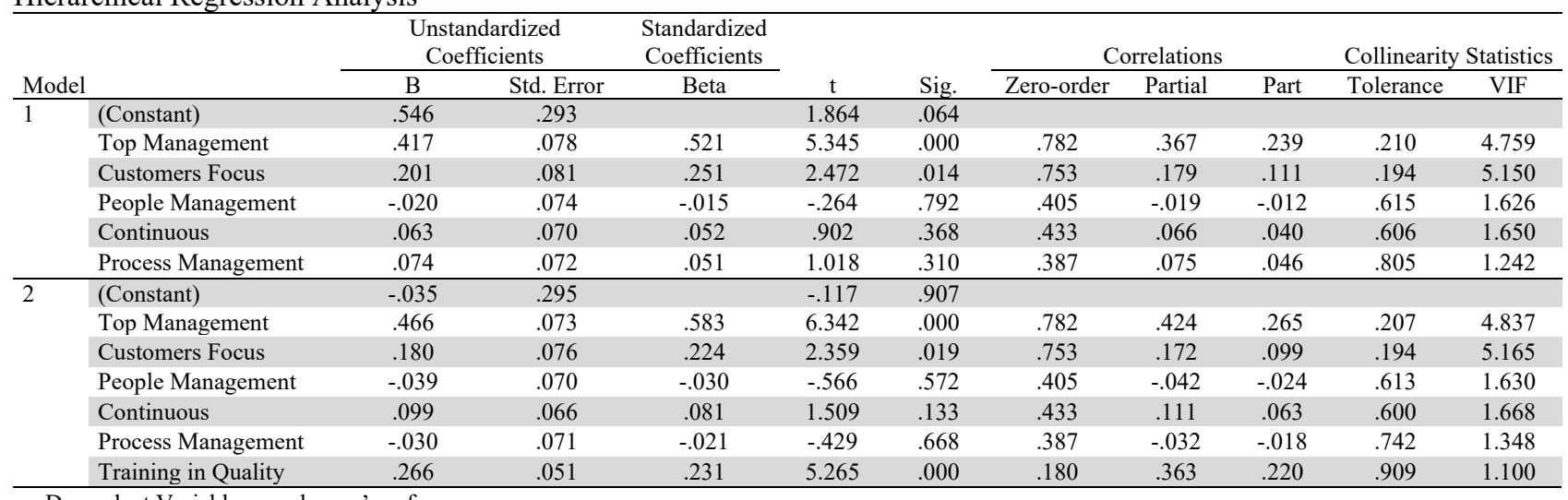

a. Dependent Variable: employees' performance

Excluded Variables ${ }^{a}$

\begin{tabular}{|c|c|c|c|c|c|c|c|c|}
\hline \multirow[b]{2}{*}{ Model } & & \multirow[b]{2}{*}{ Beta In } & \multirow[b]{2}{*}{$\mathrm{t}$} & \multirow[b]{2}{*}{ Sig. } & \multirow[b]{2}{*}{ Partial Correlation } & \multicolumn{3}{|c|}{ Collinearity Statistics } \\
\hline & & & & & & Tolerance & VIF & $\begin{array}{l}\text { Minimum } \\
\text { Tolerance }\end{array}$ \\
\hline 1 & Training in Quality Management & $.231^{\mathrm{b}}$ & 5.265 & .000 & .363 & .909 & 1.100 & .194 \\
\hline
\end{tabular}


The coefficient also suggests a positive relationship between customers' focus and employees' performance. Analysis revealed no evidence of a relationship between employees' management and employees' performance. It also revealed that there is no evidence of a significant relationship between continuous improvement and employees' performance. Lastly, there is no evidence of a significant relationship between the management process and employees' performance. On proceeding to the second stage of the regression analysis, results showed that the model is significant $F(6,183)=65.017, p<0.01$, (Table 3 ), This indicates that the second stage of the hierarchical regression analysis is significant, meaning that there are significant TQM enablers present it the model. The analysis also revealed a correlation coefficient $r=0.825$, (Table 2). which tells that moderator (Training in quality management) increased the correlation between employees' performance and the TQM enablers. It was recorded that R-squared increased by 0.048 . The coefficient table showed that the top management commitment coefficient a has a significant positive impact on employees' performance, $b=0.466, t(183)=6.342, p<0.01$, (Table 4). which is an indication that, at the influence of education/training, a unit change in top management commitment tends to affect the employees' performance by 0.466 . Analysis revealed that peoples' management has no significant effect on employees' performance. It also showed that continuous improvement and process management do not have a significant effect on employees' performance. The perceived training in management (moderator) appears as a significant predictor to employees' performance, $b=0.266, t(183)=5.265, p<0.01$ in $($ Table 4), Indicating a unit change in Training in quality management increases employees' performance by 0.266 , these finding supports the second hypothesis in the study (H2: Training in quality management is positively moderating relationship between TQM and employees' performance).

\section{Discussion}

This study aimed at examining the adoption of TQM in public hospitals. The study was based on five critical factors and how they affect the total quality management of public hospitals. It was realized that the commitment from the top management of public hospitals is an essential factor that the management should continue to look out for. The research analysis has revealed that the management has demonstrated a great commitment to greater service quality and job satisfaction of the employees in public hospitals. The research also identified the customers' focus as another essential factor that demonstrates an enhancement to the total quality management of public hospitals as the management is focused on giving medical services that meet the patient's needs. Training the employees has also been a key factor that drives the perception of the employees about their perceived level of performance in public hospitals and analysis demonstrates that training designed for employees reflects a greater performance. The fact that all other factors do not appear to be significant in the analysis does not mean that they are not important factors for the management of public hospitals to take into consideration. All factors have their way of contributing to the adoption of total quality management, however, they should be considered as important as every other significant factor. This paper aimed to examine TQM adoption impact on employee's performance in public hospitals in Turkey. A review of related literature revealed that total quality management leads to improved organizational performance, similarly, the study revealed that there is a positive relationship between all TQM practices and the employees' performance Table 2, the average correlation of $r=0.795$ and $R$-squared $=63.2 \%$. Also, the strength of effect of both practices (Top management commitment and customer focus)on employees' performance in Table 4 , were expressed in beta coefficient values ( $b=0.417$ and $b=0.201$ ) respectively, indicated the importance of paying more attention to aforementioned practices to enhance the employees performance .Finally, the Training in quality management had a coefficient value $b=0.266$ reflected the fundamental role of Training in encouraging employees involvement and to provide them with the opportunity for personal development and knowledge for doing their work efficiently. The importance of training is recognized by respondents as helpful for their work.

The findings of the study can help in identifying the most significant practices that can impact employees' performance, and to adopt the most efficient approaches in solving the underperformance of healthcare workers in the public sector by considering the following,

1-The commitment of the top management toward the quality programs

2- Meeting the patients' requirements

3-Developing effective training programs that meet the employees' needs through the collaboration between the human resources department and executive managers

For future research, it is recommended to generalize the scope of the study, covering both public and private hospitals which will provide more representative data about the employees' performance in healthcare, also to consider more performance indicator keys.

\section{Conclusion}

This paper aimed to examine TQM adoption impact on employee's performance in public hospitals in Turkey, A review of related literature revealed that total quality management leads to improved organizational performance The importance of this paper was in exploring new predictors of TQM adoption and identifying the role that training in quality management plays in TQM adoption in Turkey. The moderation effects based on Training in quality management may provide us with a greater. Understanding how TQM adoption can be influenced by dedicated training programs in public hospitals, the study 
can be used to develop a framework that can be useful for Turkish hospitals in implementing TQM practices and improving their efficiency and performance.

\section{Acknowledgment}

The authors would like to express their gratitude to Prof. Dilber Çağlar Onbasıglu, for assisting to this study. The authors also like to thank their families for their valuable support during the research.

\section{References}

Ahmed, A. O., \& Idris, A. A. (2020). Examining the relationship between soft total quality management (TQM) aspects and employees' job satisfaction in "ISO 9001" Sudanese oil companies. The TQM Journal, 33(1), 95-124. doi: 10.1108/TQM05-2019-0147.

Ahmed, P. K., Loh, A. Y., \& Zairi, M. (1999). Cultures for continuous improvement and learning. Total Quality Management, 10(4-5), 426-434.doi: 10.1080/0954412997361.

Al-khalifa, K. N., \& Aspinwall, E. M. (2000). The development of total quality management in Qatar. The TQM Magazine. 12(3), 194-204.

ASQ (2018). History and Evolution of Total Quality Management (TQM). Learn About Quality.

Batalden, P. B., \& Davidoff, F. (2007). What is "quality improvement" and how can it transform healthcare?. Quality and Safety in Health Care 16(1), 2-3. doi: 10.1136/qshc.2006.022046.

Benson, P. G., Saraph, J. V., \& Schroeder, R. G. (1991). The effects of organizational context on quality management: an empirical investigation. Management science, 37(9), 1107-1124.. doi: 10.1287/mnsc.37.9.1107.

Boer, H., Berger, A., Chapman, R., \& Gertsen, F. (Eds.). (2017). CI changes from suggestion box to organisational learning: continuous improvement in Europe and Australia: Continuous Improvement in Europe and Australia. Routledge.

Chelsea Goforth (2015). Using and Interpreting Cronbach's Alpha | University of Virginia Library Research Data Services + Sciences. University of Virginia Library. Retrieved (https://data.library.virginia.edu/using-and-interpreting-cronbachsalpha/).

Deming, W. E. (2019). Out of the Crisis. The MIT Press.

Duggirala, M., Rajendran, C., \& Anantharaman, R. N. (2008). Provider-perceived dimensions of total quality management in healthcare. Benchmarking: An International Journal, 15(6).

Feigenbaum, A. V. (1983). Total Quality Control Third Edition. Tema1 O Sistema Da Qualidade McGraw-Hill Book Company.

Flynn, B. B., Schroeder, R. G., \& Sakakibara, S. (1995). The impact of quality management practices on performance and competitive advantage. Decision sciences, 26(5), 659-691.

Galloway, L. (1998). Quality perceptions of internal and external customers: a case study in educational administration. The TQM magazine, 10(1), 20-26. doi: 10.1108/09544789810197774.

Glen, D. H., Besterfield, C., \& Besterfield-Michna. (2012). Total Quality Management. $3^{\text {rd }}$ ed.

Goetsch, D. L., \& Davis, S. B. (2016). Quality management for organizational excellence. Upper Saddle River, NJ: Pearson.

Hoyle, D. (2017). ISO 9000 Quality Systems Handbook -Increasing the Quality of an Organization's Outputs.

Idris, M. A., \& Zairi, M. (2006). Sustaining TQM: a synthesis of literature and proposed research framework. Total Quality Management and Business Excellence, 17(9), 1245-1260.

Jeston, J., \& Nelis, J. (2008). Business Process Management Practical Guidelines to Successful Implementations. 1542. $2^{\text {nd }}$ ed.

Juran, J., \& Godfrey, A. (1998). Juran's Quality Handbook, $5^{\text {th }}$ ed.

Kanji, G. K. (2002). Performance measurement system. Total Quality Management, 13(5), 715-728.

Kanji, G. K. (2012a). Measuring Business Excellence. Taylor and Francis.

Kanji, G. K. (2012b). Measuring Business Excellence.

Kueng, P. (2000). Process Performance Measurement System: A Tool to Support Process-Based Organizations. Total Quality Management, 11(1), 67-85. doi: 10.1080/0954412007035.

Lanham, H. J., McDaniel Jr, R. R., Crabtree, B. F., Miller, W. L., Stange, K. C., Tallia, A. F., \& Nutting, P. A. (2009). How improving practice relationships among clinicians and nonclinicians can improve quality in primary care. The Joint Commission Journal on Quality and Patient Safety, 35(9), 457-AP2.

Lenka, U., Suar, D., \& Mohapatra, P. K. (2010). Soft and hard aspects of quality management practices influencing service quality and customer satisfaction in manufacturing-oriented services. Global Business Review, 11(1), 79-101.

Ljungström, M., \& Klefsjö, B. (2003). Implementation obstacles for a work-development-oriented TQM strategy. Quality Control and Applied Statistics, 48(5), 529-532.

Lopez-Sanchez, M., Miralles, J. C., \& Musavi, A. (2009, July). Approaches to Hospital Process Management. In CCIA (pp. 409-418).

Micklewright, M. (2010). What Would Deming Probably Think of Today's Movements?

Oakland, J. S. (2014). Total Quality Management and Operational Excellence: Text with Cases.

Palo, S., \& Padhi, N. (2003). Measuring effectiveness of TQM training: an Indian study. International Journal of Training and Development, 7(3), 203-216. 
Rad, A. M. M. (2005). A survey of total quality management in Iran: Barriers to successful implementation in health care organizations. Leadership in Health Services, 18(3).

Rees, C. J., \& Ed, D. (2001). Employee selection in a total quality management context: Taking a hard look at a soft issue. Total Quality Management, 12(7-8), 855-860.

Samson, D., \& Terziovski, M. (1999). The relationship between total quality management practices and operational performance. Journal of Operations Management, 17(4), 393-409.

Schneider, B., \& Bowen, D. E. (1985). Employee and customer perceptions of service in banks: Replication and extension. Journal of Applied Psychology, 70(3), 423.

Sun, H. (2000). Total quality management, ISO 9000 certification and performance improvement. International Journal of Quality \& Reliability Management, 17(2).

Vouzas, F., \& Psychogios, A. G. (2007). Assessing managers' awareness of TQM. The TQM magazine, 19(1).

Walker Jr, O. C., \& Ruekert, R. W. (1987). Marketing's role in the implementation of business strategies: a critical review and conceptual framework. Journal of Marketing, 51(3), 15-33.

Weiner, B. J., Alexander, J. A., Shortell, S. M., Baker, L. C., Becker, M., \& Geppert, J. J. (2006). Quality improvement implementation and hospital performance on quality indicators. Health Services Research, 41(2), 307-334.

Wheelen, T. L., Hunger, J. D., Hoffman, A. N., \& Bamford, C. E. (2017). Strategic management and business policy (p. 55). Boston, MA: pearson.

Zairi, M. (1992). The art of benchmarking: using customer feedback to establish a performance gap. Total Quality Management, 3(2), 177-188.

Zhang, Z., Waszink, A. B., \& Wijngaard, J. (2000). An instrument for measuring TQM implementation for Chinese manufacturing companies. International Journal of Quality \& Reliability Management, 17(7), 730-55.

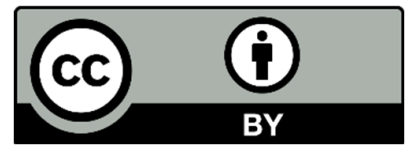

C 2021 by the authors; licensee Growing Science, Canada. This is an open access article distributed under the terms and conditions of the Creative Commons Attribution (CCBY) license (http://creativecommons.org/licenses/by/4.0/). 